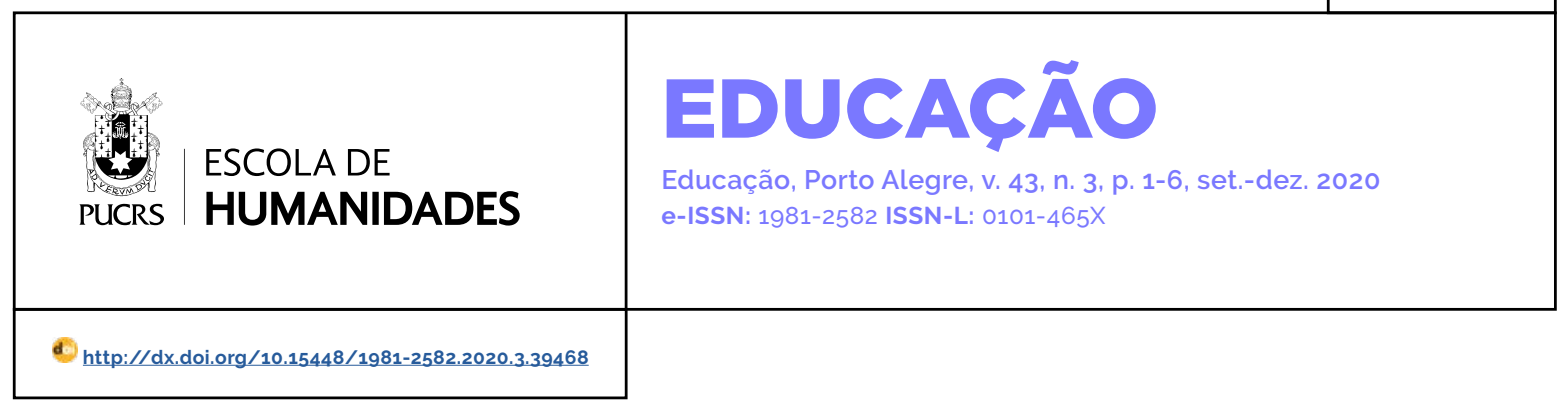

SEÇÃO: ENTREVISTA COMEMORATIVA

\title{
A experiencia de 30 anos de trabalho como secretária em um programa de pós-graduação em Educação
}

The experience of 30 years of work as a secretary in a graduate program in Education

\section{Edla Eggert ${ }^{1}$}

orcid.org/0000-0002-1980-7053

edla.eggert@pucrs.br

\section{Andreia Mendes dos}

\section{Santos $^{1}$}

orcid.org/0000-0001-7013-0239

andreia.mendes@pucrs.br

\section{Willian De Ávila ${ }^{1}$}

orcid.org/0000-0002-5276-5684 willian.avila@edu.pucrs.br

Recebido em: 25/10/2020 Aprovado em: 5/12/2020. Publicado em: 8/3/2021.

\section{(c) (1)}

Artigo está licenciado sob forma de uma licença Creative Commons Atribuição 4.0 Internacional.
Para nós, representantes docentes e discente, realizar esta entrevista foi um dia muito comemorativo, pois a entrevista com a nossa secretária mobiliza a sua memória de histórias de 30 anos de trabalho junto ao Programa de Pós-Graduação em Educação da Pontificia Universidade Católica do Rio Grande do Sul (PUCRS), que no ano de 2022 completará 50 anos. Nossas festividades se iniciam pela celebração dos 30 anos do trabalho técnico da secretária Anahi Azevedo, um momento muito especial. E parar para pensar sobre esse tempo de permanência pelo programa é pensar em muitas idas e vinda que nós professoras, professores e estudantes vamos em busca das informações e encaminhamentos de tudo que produzimos. Essa entrevista tem o objetivo de rememorar aspectos com o desejo de compartilhar e marcar importante período do programa que, muito em breve, vai comemorar 50 anos. Tais elementos foram trazidos durante a entrevista com Anahi, que acompanham mais da metade da história do PPGEDu e, então, nos possibilita olharmos para nossa caminhada na formação de pesquisadoras e pesquisadores na área da Educação Brasileira, compondo, desse modo, um pedacinho da história da educação brasileira. Uma história que apresenta um aspecto ainda mais desafiador porque estamos no meio de uma pandemia, com mudanças inusitadas no formato de docente e de gestão, que todos nós tivemos que aprender a alterar/suspender nossos modos de viver. ${ }^{2}$ Antes de mais nada, obrigada Anahí.

\section{Queremos saber um pouco da tua trajetória.}

Eu escrevi alguma coisa com aquele roteirinho que vocês me passaram. Eu fui contratada pela PUC em 1990. Na época eu tinha 24 anos, recém- casada. Foi um ano de muitas mudanças na minha vida. Eu fui indicada para trabalhar na universidade por uma amiga, uma amiga de infância que trabalhava já há alguns anos lá na PUCRS. Ela ficou sabendo dessa vaga no PPG Educação e me indicou para a professora Celina Faillace que, na 
época, era encarregada da secretaria. Naquele período, anos 90, a secretaria do PPGEDU tinha um professor como encarregado. Então, fui entrevistada pela professora Celina, fiz os testes, que eram de datilografia, conhecimentos de secretaria (documentos e atendimento) e conhecimentos gerais, não tinha o computador... Era datilografia mesmo. Depois que eu fiz a primeira entrevista, passei para segunda fase do processo, que era uma entrevista com a coordenação, na ocasião a coordenadora era a professora Maria Emilia Engers. Há pouco tempo ela esteve lá na PUC me visitando, eu a apresentei para a Profa. Edla Eggert. Comecei a trabalhar na PUCRS em 5 de novembro de 1990.

Naquela época, a secretaria era composta pela professora Celina, encarregada da secretaria, e mais três secretárias. Eu entrei como secretária da coordenação, ficava na ante sala da coordenação, ligada diretamente à coordenadora. Eu fazia, juntamente com a coordenadora, as seguintes atividades: agenda, convites para professores visitantes, controle acadêmico dos alunos, todos os trâmites de projetos, trâmites com as agências de fomento como a Capes, CNPq, Fapergs e outras. Com a transferência da professora Celina para a Pró-reitoria de Graduação, eu fui para a secretaria. Então, dali em diante, eu fiquei só na secretaria. Entrei na Universidade como "secretária 2" em 1990, e em 2001 eu fui promovida para "secretária 1". Naquele periodo, a secretária 1 era responsável pela secretaria do PG. O Lato Sensu ficava também junto com o Stricto Sensu, nessa mesma secretaria. Em 2017, o Lato passou a fazer parte da secretaria da graduação.

Vocês colocaram no roteiro sobre como eu dividiria essas etapas de experiências. Bem... eu dividiria muito em função das trocas de coordenadores, porque sempre na troca da coordenação, sentimos a diferença em muitos aspectos, as pessoas são diferentes, as gestões ficam diferentes. Muita coisa modifica na secretaria. Querendo ou não, as coisas ficam diferentes, as pessoas têm outros jeitos de ver os processos da secretaria, têm outros jeitos de resolver as dificuldades enfrentadas no dia a dia. Então, eu acho que as mudanças são muito em função das trocas de coordenação mesmo.
Tivemos um total 11 coordenadores. Eu convivi com sete, foram eles: a professora Maria Emilia Engers, fiquei oito anos com ela (1990-1997); a professora Nara Guazelli (1998-2000); o professor Juan Mosquera, com quem fiquei 8 anos na secretaria (2001-2008); depois o professor Marcos Villela (2009-2011); a professora Marilia Morosini (2012-2012); a Prof. Isabel de Moura (2013-2016); e hoje é a professora Edla Eggert (2017-2020).

As mudanças sempre são significativas e impactantes, nessa trajetória. Além das mudanças da coordenação teve todas as mudanças de dentro Universidade também. Antes de sermos escolas como hoje, teve outras mudanças. Tivemos outras mudanças e fomos caminhando e nos adaptando. A mudança mais significativa para mim foi quando a universidade mudou para o modelo de Escolas, porque foi aí que tivemos muitas mudanças, tanto na estrutura organizacional como na estrutura física, secretaria, prédio, salas, gabinetes de professores. Por um ano a secretaria ficou junto com a secretaria do Serviço Social, inicialmente ainda no prédio 15. Toda a minha vida profissional dentro da PUCRS foi ali, no prédio 15 e ai a gente mudou para outro formato de secretaria, para secretarias integradas e, também, mudamos de prédio, fomos para o prédio 8, para que as secretárias dos PGs ficassem numa mesma sala, os sete programas na Escola de Humanidades. Essa mudança foi bem interessante, é bom para todas nós trabalharmos juntas. Ali, nós somos sete secretárias de programas, as sete trabalham com as mesmas atividades, com os mesmos prazos, então a gente se ajuda muito. Ficou muito bom, penso que foi uma visão "bem legal" de quem pensou essa situação. Vejo que nesses 30 anos mudou muita coisa na minha vida, no programa, na universidade, eu como pessoa, como profissional, mas foi bom, foi bom esses 30 anos, foi muito bom... acho que vou chorar... [emoção].

\footnotetext{
Anahi, quando tu falas desta questão de perceber a tua trajetória, enfim, o teu processo de mudança, tua formação. Tu ainda estavas fazendo faculdade quando tu entrastes ou já tinhas te formado?
} 
Quando eu entrei na PUC, eu não tinha faculdade, eu não tive muito incentivo para fazer faculdade, minha familia, na época, não achava tão importante... não me incentivaram a fazer faculdade. Mas quando eu entrei na PUC eu pensei: como eu vou trabalhar na universidade sem ter uma faculdade? Esse foi meu pensamento...

Fiz o Curso de Pedagogia, na FAFIMC, em Viamão, e a Pós-graduação em Alfabetização: o jogo da Leitura e da Escrita, na PUCRS. A PUC me incentivou a estudar e a me formar.

A PUC não foi o teu primeiro emprego. Eu tinha 24 anos quando comecei a trabalhar lá, esse já era o meu quarto emprego. Eu comecei a trabalhar com 18 anos. Comecei no comércio e, depois, eu trabalhei no Banco Itaú. E, no dia 5 de novembro de 1990, comecei na PUC.

No teu exercício de secretária tu foi aprendendo pela experiência!

Sim, sim pela experiência, na experiência, eu não tinha experiência de secretária. Não fiz o curso de secretariado, na época não tinha essa exigência. Mas eu penso que também é na experiência de uma secretaria, principalmente uma secretaria de pós-graduação, que a gente aprende os processos de cada Curso e de cada Escola. Na experiência, no convívio, nas atividades do dia a dia.

\section{E a mudança quando o programa ganhou o} Proex? Como foi essa mudança, qual a diferença do que era um programa que era nota 4 e ai foi para 5 , e aí foi para 6 , como que foi isso?

Sim, porque as preocupações só aumentaram, professora. Um curso 4, depois 5 como a gente era, as preocupações eram diferentes. Com a nota 6, veio o PROEX, veio a preocupação com o financeiro, com a distribuição da verba extra que o programa recebe da Capes. A administração do Proex é um trabalho paralelo dentro da secretaria. É um trabalho distinto do trabalho da secretaria, que exige muito, muito empenho. Principalmente, porque é o financeiro que é muito preocupante, a senhora sabe que toda situação do Proex, "tira o sono da gente"...
Percebemos você como alguém que está sempre sendo cautelosa e essa é uma das coisas que no mundo da secretaria é muito importante. Esse cuidado e essa exigência do trabalho paralelo é valiosa, você é a guardiã, essa é a palavra. Você enxerga, que muitas vezes faz esse papel de guardiã?

Então... não tinha pensado desse jeito professora, mas eu acho que... que pode ser mesmo, porque já foi assim com o Proex anterior ao seu, da professora Isabel. Eu realmente, eu guardo "aquelas caixinhas" para onde eu vou. Na mudança do Prédio 15 para o Prédio 8, minha preocupação era me abraçar naquelas caixinhas, porque é uma preocupação eterna. Cada coordenadora que sai da coordenação, o nome dela segue ali, o CPF dela está ali, então eu guardo aquela documentação como se fosse uma guardiã mesmo, mas não tinha pensado nesse sentido. Todas aquelas caixas... Meu Deus! A gente tinha, no prédio 15, uma sala de aula com vários arquivos, com muitos arquivos e na mudança a gente teve que fazer reciclagens, porque teve um periodo que não havia computador, não tinha como armazenar virtualmente, era papel mesmo! E isso a gente não podia colocar fora, não pode colocar a "história" fora, muitos materiais estão guardados em uma sala no quinto andar (prédio 8), ainda não conseguimos organizar do jeito que tem que ser, mas está tudo guardado lá. Eu coloquei indicação nas caixas: história do programa, história do programa, história do programa. Então, tem várias caixas com a história do programa, história e, também, materiais de alunos, professores, disciplinas, porque até começarmos a armazenar os materiais no sistema, tínhamos tudo arquivado material físico mesmo.

As mudanças que tu dizes marcam, com as trocas de coordenação, e rotinas, com diferentes pessoas e impactos. Mas, se tu pudesses recuperar uma memória de cada uma dessas coordenações, de que forma elas te marcaram?

Olhe, tu sabes que todas as pessoas que passaram ali pela minha vida sempre me marcaram e 
sempre me deixaram alguma coisa boa. A minha primeira coordenadora foi a professora Maria Emilia, trabalhamos muito tempo juntas, "uma vida", mantemos contato até hoje. Ela era muito exigente, me ensinou muito. A professora Nara, ela trabalhava muito sozinha, foi na gestão da professora Nara que eu fui para a secretaria. Com o prof. Juan, já foi bem diferente, eu trabalhava ao lado dele o tempo inteiro, mas continuei com as atividades gerais da secretaria e junto à coordenação. $O$ prof. Juan foi muito importante na minha vida, me ensinou muito. O professor Marcos, que também é superindependente na coordenação, me deu bastante autonomia no trabalho da secretária do PPG. A professora Marilia, tinha o mesmo sistema do professor Juan, eu trabalhava bem próximo dela junto à coordenação e com as atividades da secretaria. Na gestão da professora Isabel a gente já trabalhava na secretaria junto com o Serviço Social. Já era a secretaria integrada, mas ela era bem autônoma nas atividades da coordenação. E a professora Edla, destaco que ela colabora muito com a secretaria. Ela se envolve e entende como funcionam as tarefas dentro de cada processo. Agradeço a cada um dos coordenadores, pois todos foram muito importantes na minha trajetória no programa e na minha vida.

\section{A integração das áreas agora que são sete programas juntos. Como é que tu vês isso?}

Vejo como uma coisa boa, mas na época que começou, que começaram a cogitar eu disse: Meu Deus! Como vai ficar esse "monte" de secretarias juntas? Como que a gente vai fazer atendimento? Como vamos identificar os alunos?

Hoje eu acho muito bom trabalharmos juntas. Por exemplo, na época do relatório CAPES, está todo mundo fazendo o relatório, todo mundo compartilha suas preocupações, suas perspectivas. Se amanhã eu tenho que entregar isso, no final do mês tem aquilo, então fica mais fácil quando a gente trabalha numa mesma perspectiva. Eu gosto desse modelo, acho importante a integração que temos dentro da secretaria. Eu nunca gostei de trabalhar sozinha, apesar de todos esses anos eu trabalhar numa sala sozinha, eu gosto de trabalhar com mais gente por perto mesmo, eu prefiro falar, conversar, perguntar.

\section{E quanto aos alunos, tu percebes diferença nesses 30 anos? Você percebe a diferença nos alunos nesses 30 anos?}

Sim. Percebo a diferença nos alunos. Percebo a diferença que os alunos de hoje são muito mais independentes do que eram antigamente. Os alunos antigamente faziam fila na secretaria, apesar de ter muito mais secretárias, aquela secretaria vivia cheia. E hoje, mesmo sendo esses sete programas, é difícil a secretaria estar cheia de aluno. Claro que a tecnologia ajuda muito.

Então, claro que a mudança do aluno se dá também com toda essa mudança tecnológica, porque hoje passamos um e-mail para os alunos, para todos eles numa só vez, com informações diversas. A grande maioria dos alunos acessa o e-mail institucional. Assim fica muito mais fácil o alcance e a disseminação das informações. Antigamente, a gente não tinha e-mail, porque não tinha internet, não tinha toda essa tecnologia, então essa mudança valeu muito porque, realmente, hoje eles são muito mais independentes. Hoje, numa mensagem de WhatsApp a gente resolve uma dificuldade individual e até um problema do grupo. Há muitos anos os alunos telefonavam ou iam na secretaria marcar um horário com a coordenação, a agenda do coordenador era sempre cheia, porque sempre tinha vários alunos tentando resolver problemas individuais, só que eles tinham que ir à secretaria ou telefonar, não tinha uma outra possibilidade, era tudo manual.

\section{E o número de alunos variou muito?}

Eu não tenho certo número de alunos, mas a gente tem quase o mesmo número. O stricto sensu se mantém mais ou menos com o mesmo número de alunos. A gente já teve mais um pouco de alunos que temos hoje, mas tínhamos mais professores.

Nessa trajetória, tu percebes o programa se reestruturando para dar conta dessas transformações, como percebes a transformação para 


\section{a Escola de Humanidades, a transformação da redução do quadro de professores?}

Sim. A mudança se dá, por exemplo, com os professores... teve época que os professores tinham 2 , 3 orientandos, hoje os professores não têm menos de 8 orientandos, são mudanças bem grandes. Tinha alguns professores, quando eu entrei, que não eram doutores, não tinham doutorado. Tinham professores que estavam cursando doutorado, então a mudança no programa de 1990 para hoje. foi enorme, porque hoje o professor que não tem doutorado ele nem vai entrar no programa, é uma exigência da Capes para um Curso com a nossa avaliação. Naquela época, quando eu entrei, tinham vários professores que tinham só mestrado e estavam fazendo doutorado.

E as linhas de pesquisa, grupos de pesquisa, núcleos, tu viste se modificar a maneira deles serem pensados no programa?

É teve várias alterações em termos de linhas de pesquisa, teve periodos que elas se alargaram mais e depois se enxugou mais. Hoje temos três linhas, mas já tivemos quatro linhas de pesquisa. Já se pensou em duas linhas de pesquisa. Os projetos de pesquisa dos professores, antigamente, tinham vários, vários, vários projetos e, agora, são projetos mais condensados, mais tipo "guarda-chuva". Os professores agora, têm um projeto guarda-chuva e os outros projetos embaixo, mas não é aquele "monte" de projetos como era antes, é mais enxuto hoje do que antigamente no meu entendimento.

Como tu disseste, os coordenadores impactam algumas rotinas da secretaria. E, como as mudanças no Governo Federal impactam na pós-graduação?

Pois é, não me recordo de uma coisa que tenha impactado dentro da universidade, essa função de política dentro das universidades fica muito forte. Mas a PUC é um lugar que a gente se sente muito seguro, então não me recordo de ter algo. Eu me lembro de a gente sair do trabalho com algumas preocupações, mas não ali dentro da universidade. E impactando no pós-graduação, diretamente, a gente sempre se preocupa muito com a função das bolsas, dos episódios em que vai acontecer alguma coisa, a primeira coisa que vinha no topo da lista: "Ah, vai ter corte de bolsa". Então, o corte de bolsas sempre afeta diretamente o pós-graduação, e é sempre uma preocupação que temos, que todo pós-graduação tem. Graças a Deus, nosso programa sempre teve um número bem razoável de bolsas. Mas, claro, nem sempre conseguimos contemplar a todos.

Tem alguma outra coisa que tu tenhas colocado nas tuas anotações e que a gente não conversou aqui?

Tu sabes que eu sempre me emociono quando eu falo do tempo, da vida, história de vida é sempre... [emoção] eu gosto muito de histórias de vida. Teve professores que trabalharam com a gente, não sei se vocês vão se recordar, mas a professora Maria Helena Abrahão trabalhava com histórias de vida, os projetos dela geralmente era em torno de histórias de vida. Sempre gostei muito dessa parte da pesquisa, história de vida. E hoje eu estou falando da minha história de vida, da minha história dentro da Universidade, dentro do PPG, da minha evolução como pessoa e como profissional.

A PUC entra na tua história de vida. E a PUC é a tua história de vida. Tem um pesquisador, que é da filosofia do trabalho, chamado Yves Schwartz, ${ }^{3}$ que diz que as pessoas se entregam de tal forma para o trabalho que já não sabem mais quem elas são, porque elas são o trabalho que elas fazem. E pesquisar esse campo e es-

Filósofo estudioso das atividades de trabalho, desenvolvedor do conceito de ergologia no contexto pluridisciplinar nos estudos sobre situações de trabalho. No Brasil, na área da Trabalho e Educação, estudiosas como Daysi Cunha da UFGM, têm capilarizado os estudos do filósofo em pesquisas realizadas no Brasil. Atualmente, Cunha é diretora do Instituto de Estudos Avançados IEAT/UFMG. (Cf. CUNHA SCHWARTZ, p. 201) 
cutar tua história, como vários de nós também já entrevistamos, e vimos isso que você está dizendo. Por isso que a gente fica tão guardião das coisas quando a gente se envolve com elas.

É a PUC faz parte da minha vida. [emoção...] É, eu acho que eu nunca tinha parado para pensar, nisso tudo, no tempo... porque 30 anos é muito tempo. Muitas coisas aconteceram nesse tempo, muitas mudanças aconteceram... Eu sou muito feliz com o que eu faço, com o meu trabalho, com a universidade em si, com o programa, com os professores que passaram por mim ali. Eu sou muito feliz profissionalmente.

Que legal Anahi. Christophe Dejours é outro pesquisador que vai dizer que o trabalho não é só sofrimento.

É, não pode ser sofrimento, a gente passa muito tempo trabalhando. Então, não pode ser uma coisa ruim, que te faça mal. Se é uma coisa que te deu alguma felicidade, alguma recompensa, e eu me sinto bem recompensada. Me sinto recompensada, feliz e realizada em relação ao meu trabalho.

Acho que esta é uma fase bem boa, apesar de que nesse ano a coisa complicou em função da pandemia, mas eu acho que a gente estava numa fase muito boa sim na secretaria, a organização geral, acho que a gente já tinha conseguido uma organização bem legal.

\section{Referências}

CUNHA, D. M.; SCHWARTZ, Y. A formação humana entre o conceito e a experiência do trabalho: elementos para uma pedagogia da atividade. Trabalho \& Educação, IS. l.J, v. 15, n. 1, p. 87-90, 2012. Disponivel em: https://periodicos.ufmg.br/index.php/trabedu/article/view/8834. Acesso em: 3 nov. 2020.

\section{Edla Eggert}

Doutora em Teologia pela Escola Superior de Teologia, em São Leopoldo, RS, Brasil; professora na Escola de Humanidades da Pontifícia Universidade Católica do Rio Grande do Sul (PUCRS), em Porto Alegre, RS, Brasil; coordenadora do Programa de Pós-Graduação em Educação; professora no PPGEdu e no PPG de Teologia da PUCRS, em Porto Alegre, RS, Brasil.

\section{Andreia Mendes dos Santos}

Doutora em Serviço Social pela Pontifícia Universidade Católica do Rio Grande do Sul (PUCRS), em Porto Alegre, RS, Brasil; professora na Pontificia Universidade Católica do Rio Grande do Sul junto a Escola de Humanidades (PUCRS), em Porto Alegre, RS, Brasil, nos Programas de Pós Graduação em Educação (PPGEDU) e Ciências Sociais (PPGCSociais) e na Escola de Ciências da saúde e da Vida

\section{Willian De Ávila}

Mestrando de Educação na Pontificia Universidade Católica do Rio Grande do Sul (PUCRS), em Porto Alegre, RS, Brasil. Representante discente junto ao PPGEDU/PUCRS

\section{Endereço para correspondência}

Edla Eggert

Pontificia Universidade Católica do Rio Grande do Sul Programa de Pós-Graduação em Educação

Av. Ipiranga, 6.681 , prédio $8,3^{\circ}$ andar

Partenon, 97010082

Porto Alegre, RS, Brasil 